\title{
Acclimation to extremely high ammonia levels in continuous biomethanation process and the associated microbial community dynamics
}

Tian, Hailin; Fotidis, loannis ; Mancini, Enrico; Treu, Laura; Mahdy, Ahmed; Ballesteros, Mercedes; González-Fernández, Cristina; Angelidaki, Irini

Published in:

Bioresource Technology

Link to article, DOI:

10.1016/j.biortech.2017.09.148

Publication date:

2018

Document Version

Peer reviewed version

Link back to DTU Orbit

Citation (APA):

Tian, H., Fotidis, I., Mancini, E., Treu, L., Mahdy, A., Ballesteros, M., González-Fernández, C., \& Angelidaki, I. (2018). Acclimation to extremely high ammonia levels in continuous biomethanation process and the associated microbial community dynamics. Bioresource Technology, 247, 616-623.

https://doi.org/10.1016/j.biortech.2017.09.148

\section{General rights}

Copyright and moral rights for the publications made accessible in the public portal are retained by the authors and/or other copyright owners and it is a condition of accessing publications that users recognise and abide by the legal requirements associated with these rights.

- Users may download and print one copy of any publication from the public portal for the purpose of private study or research.

- You may not further distribute the material or use it for any profit-making activity or commercial gain

- You may freely distribute the URL identifying the publication in the public portal 


\section{Accepted Manuscript}

Acclimation to extremely high ammonia levels in continuous biomethanation process and the associated microbial community dynamics

Hailin Tian, Ioannis A. Fotidis, Enrico Mancini, Laura Treu, Ahmed Mahdy, Mercedes Ballesteros, Cristina González-Fernández, Irini Angelidaki

PII: S0960-8524(17)31713-3

DOI: https://doi.org/10.1016/j.biortech.2017.09.148

Reference: BITE 18976

To appear in:

Bioresource Technology

Received Date:

21 August 2017

Revised Date: 19 September 2017

Accepted Date:

21 September 2017

Please cite this article as: Tian, H., Fotidis, I.A., Mancini, E., Treu, L., Mahdy, A., Ballesteros, M., GonzálezFernández, C., Angelidaki, I., Acclimation to extremely high ammonia levels in continuous biomethanation process and the associated microbial community dynamics, Bioresource Technology (2017), doi: https://doi.org/10.1016/ j.biortech.2017.09.148

This is a PDF file of an unedited manuscript that has been accepted for publication. As a service to our customers we are providing this early version of the manuscript. The manuscript will undergo copyediting, typesetting, and review of the resulting proof before it is published in its final form. Please note that during the production process errors may be discovered which could affect the content, and all legal disclaimers that apply to the journal pertain. 


\section{Acclimation to extremely high ammonia levels in continuous}

\section{biomethanation process and the associated microbial community}

\section{dynamics}

Hailin Tian ${ }^{\text {a }}$, Ioannis A. Fotidis ${ }^{\text {a, } *, \text { Enrico Mancini }}{ }^{\text {a }}$, Laura Treu ${ }^{\text {a, b }}$, Ahmed Mahdy ${ }^{\text {c }}$, Mercedes Ballesteros ${ }^{\text {d, e }}$, Cristina González-Fernández ${ }^{\text {d }}$, Irini Angelidaki ${ }^{\text {a }}$

${ }^{\text {a }}$ Department of Environmental Engineering, Technical University of Denmark, Bygningstorvet Bygning 115, DK-2800 Kgs. Lyngby, DK

${ }^{\mathrm{b}}$ Department of Agronomy, Food, Natural Resources, Animal and Environment (DAFNAE), Viale dell'Università, 16, 35020 Legnaro(Padova), Italy

${ }^{\mathrm{c}}$ Department of Agricultural Microbiology, Faculty of Agriculture, Zagazig University, 44511 Zagazig, EG

d Biotechnological Processes for Energy Production Unit - IMDEA Energy, 28935 Móstoles, Madrid, ES

${ }^{e}$ Biofuels Unit - Research Center for Energy, Environment and Technology (CIEMAT), 28040 Madrid, ES

*Corresponding Author: Ioannis A. Fotidis, Department of Environmental Engineering, Technical University of Denmark, Bygningstorvet Bygning 115, DK-2800 Kgs. Lyngby, Denmark, Phone: (+45) 45251418; Fax: (+45) 45933850; e-mail: ioanf@env.dtu.dk 


\section{Abstract}

Acclimatized anaerobic communities to high ammonia levels can offer a solution to the ammonia toxicity problem in biogas reactors. In the current study, a stepwise acclimation strategy up to $10 \mathrm{~g} \mathrm{NH}_{4}{ }^{+}-\mathrm{N} \mathrm{L}^{-1}$, was performed in mesophilic $\left(37 \pm 1^{\circ} \mathrm{C}\right)$ continuously stirred tank reactors. The reactors were co-digesting (20/80 based on volatile solid) cattle slurry and microalgae, a protein-rich, $3^{\text {rd }}$ generation biomass. Throughout the acclimation period, methane production was stable with more than $95 \%$ of the uninhibited yield. Next generation 16S rRNA gene sequencing revealed a dramatic microbiome change throughout the ammonia acclimation process. Clostridium ultunense, a syntrophic acetate oxidizing bacteria, increased significantly alongside with hydrogenotrophic methanogen Methanoculleus spp., indicating strong hydrogenotrophic methanogenic activity at extreme ammonia levels $\left(>7 \mathrm{~g} \mathrm{NH}_{4}{ }^{+}-\mathrm{N} \mathrm{L}^{-1}\right)$. Overall, this study demonstrated for the first time that acclimation of methanogenic communities to extreme ammonia levels in continuous AD process is possible, by developing a specialised acclimation AD microbiome.

\section{Keywords}

Methane; ammonia inhibition; microbial community; syntrophic acetate oxidizer;

\section{Methanosarcina.}

\section{Introduction}

Anaerobic digestion (AD) is a sustainable technology that can produce biogas and nutrient-rich bio-fertilizer from a broad variety of residual biomass (e.g. agricultural waste, food waste and sewage sludge) (Karim et al., 2005). AD is a complex biological 
process, which comprises four main steps: hydrolysis, acidogenesis, acetogenesis and methanogenesis, with a variety of microorganisms mediating each step. Acetate is the main precursor of methane production which follows two major methanogenic pathways: a) aceticlastic pathway and b) hydrogenotrophic pathway (syntrophic acetate oxidation (SAO) coupled with hydrogenotrophic methanogenesis). Aceticlastic pathway is mediated by Methanosarcinaceae spp. and Methanosaetaceae spp., while Methanomicrobiales spp., Methanobacteriales spp., Methanococcales spp., Methanopyrales spp. and Methanocellales spp. mediate the hydrogenotrophic partway (Lyu \& Lu, 2015). Furthermore, there is also evidence showing that some members of Methanosarcinaceae spp. can perform both aceticlastic and hydrogenotrophic pathways (Liu \& Whitman, 2008).

Many compounds (e.g. ammonia, sulphide, light metal ions, heavy metals, organics etc.) can affect the AD microbial community, cause reactor instability with low methane yield. Ammonia is the major toxicant of the commercial AD reactors and usually derives from the degradation of urea and protein-rich substrates, such as slaughterhouse wastewater and food waste etc. Latterly, microalgae, a $3^{\text {rd }}$ generation biomass, has been considered as biomass for biogas production, because it does not compete with food supply and has a high methane potential. However, the use of protein-rich microalgae as AD substrate has been proven to be very difficult due to its high nitrogen content (Maity et al., 2014). Total ammonia (TAN) is presented as ammonium ion $\left(\mathrm{NH}_{4}{ }^{+}\right)$and free ammonia $\left(\mathrm{NH}_{3}, \mathrm{FAN}\right)$ depending on the $\mathrm{pH}$ and temperature of the aqueous phase. FAN is believed to be the most toxic form of TAN due to its high permeability into cell membrane (Massé et al., 2014). Different inhibition thresholds were reviewed in literature (Yenigün \& Demirel, 2013). However, it is generally accepted nowadays that 
TAN and FAN loads above $3 \mathrm{~g} \mathrm{NH}_{4}{ }^{+}-\mathrm{N} \mathrm{L}^{-1}$ and $0.15 \mathrm{~g} \mathrm{NH}_{3}-\mathrm{N} \mathrm{L}^{-1}$ can inhibit AD process and lower the potential methane yield of AD reactors (Nielsen \& Angelidaki, 2008; Yenigün \& Demirel, 2013).

To solve the ammonia problem, many solutions have been proposed in recent years. For example, dilution of the reactor content with water (Nielsen \& Angelidaki, 2008); air stripping (Zhang et al., 2012); addition of absorbing material (Hansen et al., 1999); lowering the operating temperature (Angelidaki \& Ahring, 1994); co-digestion with high carbon content substrate (Tsapekos et al., 2017); microbial electrochemical cell (Zhang \& Angelidaki, 2015) and bioaugmentation with syntrophic acetate oxidizing bacteria (SAOB) or methanogens (Fotidis et al., 2014b; Westerholm et al., 2012). However, many of these methods are technically complex connected with high operational costs leading to limited applicability. Acclimation of microbial consortia to high ammonia levels could provide a practical and cost-effective method to digest protein-rich substrates (Yenigün \& Demirel, 2013). A large number of investigations has demonstrated that methanogenic inocula have a high ammonia adaptation potential (Koster \& Lettinga, 1988; Parkin et al., 1983). Additionally, a recent research showed that fast and efficient acclimatization of anaerobic consortia to high ammonia levels is possible in batch and fed-batch reactors (Tian et al., 2017). However, limited information (if any) is available in literature about successful acclimation using continuous reactors (e.g. continuously stirred tank reactor (CSTR)) at extremely high ammonia levels (> $\left.7 \mathrm{~g} \mathrm{NH}_{4}{ }^{+}-\mathrm{N} \mathrm{L}^{-1}\right)$. Lack of successfully acclimatizing the process to extremely high ammonia levels could probably be attributed to the washout effect, by which inhibited microorganisms not growing fast enough at a specific retention time 
were washed out from the reactor (Tian et al., 2017). Washout is limiting operation at high rates continuous reactors without any microbial support matrix (e.g. granules).

Previous microbial community assessment studies during different acclimation processes to high ammonia levels, have reported controversial results. On one hand, there are studies indicating that the acclimation process to high ammonia levels caused a shift from aceticlastic to hydrogenotrophic methanogenesis (Schnürer \& Nordberg, 2008; Werner et al., 2014). On the other hand, Methanosarcinaceae spp. associated aceticlastic pathway has been found to be predominant at high ammonia levels (Calli et al., 2005; Karakashev et al., 2005). A more insightful and detailed understanding about the microbiome would be of great importance in further optimization of stable AD process, thus it is important to elucidate the microbial community changes during acclimation of continuous $\mathrm{AD}$ process to extremely high ammonia levels.

Therefore, the main aim of the present study was to use, for the first time, CSTR reactors fed with protein-rich microalgae ( $3^{\text {rd }}$ generation biomass) as the main substrate, to successfully acclimatize methanogenic consortia to extremely high ammonia levels (> $7 \mathrm{~g} \mathrm{NH}_{4}{ }^{+}-\mathrm{N} \mathrm{L}^{-1}$ ) overcoming the microbial washout effect. An additional aim was to reveal the effect of the ammonia acclimation process in the continuous reactors on the AD microbiome dynamics using next generation 16S rRNA gene sequencing.

\section{Material and methods}

\subsection{Inoculum and feedstock}

The inoculum derived from a full-scale mesophilic $\left(37 \pm 1^{\circ} \mathrm{C}\right)$ biogas plant $(\mathrm{Hash} \emptyset \mathrm{j}$, Denmark), fed with $70-90 \%$ animal manure and 10-30\% food industrial organic waste. Two substrates were used in this study: cattle slurry and microalgae Chlorella vulgaris. 
Cattle slurry was obtained from Hashøj Municipality, Denmark. It was sieved and stored at $-21^{\circ} \mathrm{C}$ until use. Microalgae $C$. vulgaris ( $>50 \%$ protein in dry matter), as a protein-rich substrate, was grown in mineral salt medium $(\mathrm{MBBM}-2 \mathrm{~N})$ in a raceway pond with continuous illumination at $25^{\circ} \mathrm{C}$ and pretreated according to a previous methodology (Mahdy et al., 2015) after cultivation and harvest. Specifically, a biological catalyst (Protease, Alcalase 2.5, Novozymes, Denmark) was used to hydrolyse microalgae at $\mathrm{pH} 8$. Subsequently, the inactivation of the enzyme was done by heating the hydrolytic broth to $75^{\circ} \mathrm{C}$ for 30 mins. Then the pretreated microalgal biomass was stored into freezer until use. The basic characteristics of the inoculum and substrates were shown in Table 1. Ammonium chloride $\left(\mathrm{NH}_{4} \mathrm{Cl}\right.$, Sigma-Aldrich) was used as ammonia source.

\subsection{Experimental setup}

Two lab-scale mesophilic $\left(37 \pm 1^{\circ} \mathrm{C}\right) \mathrm{CSTR}$ reactors were used in this study ( $\mathrm{R} 1$ and R2) as duplicate. Each reactor had a 2.3 and $1.8 \mathrm{~L}$ total and working volume, respectively, and was equipped with an influent and an effluent bottle, a feeding peristaltic pump, an electrical heating jacket, a water displacement gas meter and two magnetic stirrers. Both reactors were operating with a hydraulic retention time (HRT) of 23 days throughout the experiment. Cattle manure was used during the start-up period of the reactors until a steady state (defined by the variation of the methane yield less than $10 \%$ for at least ten consecutive days) occurred (data shown by Mahdy et al. (2017)). The main experiment was divided into four different phases (Table 2). A mixed substrate of cattle slurry and microalgae (20/80 VS/VS) was used throughout the experiment (P1-4). The acclimation strategy was implemented with stepwise increase of TAN concentration using ammonia chloride $\left(0.5 \mathrm{~g} \mathrm{NH}_{4}{ }^{+}-\mathrm{N} \mathrm{L}^{-1}\right.$ each step) up to $10 \mathrm{~g}$ 
$\mathrm{NH}_{4}{ }^{+}-\mathrm{N} \mathrm{L}^{-1}$ both inside the reactor and the feedstock in the influent bottle. The expected and measured TAN levels and the calculated FAN levels for both reactors are depicted in an E-supplement file.

\subsection{Analyses}

\subsubsection{Physicochemical analyses}

TS, VS, TKN and TAN were measured according to APHA (2005). The composition of biogas was measured by a gas-chromatograph equipped with a column of $1.1 \mathrm{~m} \times 3 / 16$ "Molsieve 137 and $0.7 \mathrm{~m} \times 1 / 4$ " chromosorb 108 (MGC 82-12, Mikrolab $\mathrm{A} / \mathrm{S}$, Denmark) using hydrogen as a carrier gas. The $\mathrm{pH}$ of samples retrieved from the reactor was determined immediately after retrieval in a closed bottle to minimise evaporation of $\mathrm{CO}_{2}$, by PHM99 LAB pH meter. A gas-chromatograph (HP 5890 series II) equipped with flame ionization detector and a FFAP fused silica capillary column $(30 \mathrm{~m} \times 0.53 \mathrm{~mm}$ i.d., film thickness $1.5 \mu \mathrm{m})$ was used to measure total VFA concentration inside the reactors, while nitrogen was used as carrier gas.

\subsubsection{Microbial analyses}

Triplicate samples were taken at the end of each phase to identify the microbial dynamics. After an extra cleaning step with Phenol: Chloroform: Isoamyl Alcohol (25: 24: 1) (Sigma-Aldrich), genomic DNA was extracted from the samples according to PowerSoil \& DNA Isolation Kit (MO BIO laboratories Inc., Carlsbad, CA USA). PCR amplification using universal primers 515F/806R was conducted on the V4 region of 16S rRNA gene, and next generation sequencing was performed on an Illumina MiSeq platform (Ramaciotti Centre for Genomics, Kensington, Australia). 
Raw reads were deposited in Sequence Read Archive (SRA) database (http://www.ncbi.nlm.nih.gov/sra) under the project SPR103296, and detailed sample accession numbers were provided in the E-supplement file. The raw sequences were analysed using CLC Workbench software (V.8.0.2) with microbial genomics module plug in (QIAGEN). Trimming step and chimera crossover filter were applied using the default parameters of the software to ensure the high quality of the reads. Operational taxonomic units' (OTUs) phylogenetic assignment was performed with multiple sequence alignment of fixed length trimmed (240 bp) sequences using MUSCLE software (Edgar, 2004) and Greengenes v13_5 database as reference (clustered at 97\%). New OTUs were identified when the similarity percentage with database was lower than $80 \%$, with a minimum occurrence of five reads. Maximum likelihood phylogeny was created with neighbour Joining as construction method and Jukes Cantor as nucleotide substitution model, while 100 bootstrap replicates was used to test the certainty of the evolutionary relation and distance. Rarefaction curves were used to evaluate the sequencing depth for each sample, which was presented in the E-supplement file. Chao 1 bias-corrected index was used to evaluate Alpha diversity, while Beta diversity was represented as Principal Component Analysis (PCA) performed by STAMP software. Statistics regarding the sequencing results and taxonomic assignment were reported in the E-supplement file. The taxonomic assignment of the most interesting OTUs (relative abundance higher than $1 \%$ for bacteria and $0.1 \%$ for archaea) was based on the results from BLASTN search against 16S ribosomal RNA sequences (Bacteria and Archaea) database and CLC software, and details can be found in the E-supplement file.

Microbial relative abundance and corresponding folds change were represented as heat maps (Fig. 3) using Multi experiment viewer software (MeV 4.9.0) (Saeed et al., 2006). 


\subsection{Calculations and statistics}

The FAN concentration was calculated by the following equation:

$$
\mathrm{FAN}=\frac{\mathrm{TAN}}{1+\frac{10^{-\mathrm{pH}}}{K_{a}}}
$$

Where $K_{a}$ is the dissociation constant, which equals to $1.29 \times 10^{-9}$ at mesophilic condition. All statistical analyses and the plotted data of the reactor performance (methane yield, $\mathrm{pH}$ and VFA variation) were made using the OriginLab program (OriginLab Corporation, Northampton, Massachusetts). One-way ANOVA was used to evaluate the statistically significant differences $(p<0.05)$ of the reactor performance. STAMP software was used to identify the OTUs with significant changes in relative abundance of different samples (Parks \& Beiko, 2010).

\section{Results and discussion}

\subsection{Reactor performance}

During P1, an average methane yield of $338 \pm 14$ and $338 \pm 16 \mathrm{NmL} \mathrm{CH}_{4} \mathrm{~g}^{-1} \mathrm{VS}$ under steady state was observed for R1 and R2, respectively (Fig. 1a), which was used as the baseline to evaluate any instability during the acclimation process (P2-4). The methane production for both reactors was mostly stable throughout the ammonia acclimation period; only R1 had two brief periods (during P3 and P4) with statistically $(p<0.05)$ lower methane production compared to baseline $(\mathrm{P} 1)$ but in both cases, it recovered in less than half HRT. Thus, an average methane yield of $322 \pm 37$ and $327 \pm$ 
$17 \mathrm{NmL} \mathrm{CH}_{4} \mathrm{~g}^{-1}$ VS was achieved for R1 and R2, respectively, throughout the acclimation period (P2-4), which were above $95 \%$ of the methane yields during the baseline period (P1). By contrast, previous studies have reported inhibition in continuous reactors exposed to ammonia concentrations above $5 \mathrm{~g} \mathrm{NH}_{4}^{+}-\mathrm{N} \mathrm{L}^{-1}$ (Yenigün \& Demirel, 2013). Additionally, another modelling study even defined $10 \mathrm{~g}$ $\mathrm{NH}_{4}{ }^{+}-\mathrm{N} \mathrm{L}^{-1}$ as the absolute AD-death threshold (Liu \& Sung, 2002). Interestingly, both reactors in the present study had a stable performance at extreme ammonia levels contradicting/challenging this theoretical threshold. To date, only methanogenic cultures cultivated in batch reactors have remained active at extremely high ammonia levels (> $\left.7 \mathrm{~g} \mathrm{NH}_{4}{ }^{+}-\mathrm{N} \mathrm{L}^{-1}\right)($ Koster \& Lettinga, 1988).

The VFA accumulation (Fig. 1b) in R2 was always lower than R1 during the acclimation process. However, both reactors had VFA concentration below $2400 \mathrm{mg}$ $\mathrm{HAc} \mathrm{L}^{-1}$ at the highest ammonia levels with stable methane yield. That was in accordance with previous studies where methane production wasn't affected when the VFA reaches $3000 \mathrm{mg} \mathrm{HAc} \mathrm{L}^{-1}$ and inhibition was only observed above $4000 \mathrm{mg}$ HAc $\mathrm{L}^{-1}$ (Ahring et al., 1995; Siegert \& Banks, 2005). At the same time, pH fluctuated between 8.4 and 7.7 (Fig. 1c), which was within the normal range (6.5-8.5) for AD process.

Therefore, all the reactor performance parameters denote a stable and efficient acclimation process to extremely high ammonia levels. This process stability could be attributed to two basic reasons. First, even though TAN levels were increased 1.6-folds to $10 \mathrm{~g} \mathrm{NH}_{4}{ }^{+}-\mathrm{N} \mathrm{L}^{-1}$, the FAN levels were stable $\left(800-850 \mathrm{mg} \mathrm{NH}_{3}-\mathrm{N} \mathrm{L}^{-1}\right.$, E-supplement file) throughout the experiment due to the lower $\mathrm{pH}$ along with the ammonia increase (Fig. 1c). This supports the hypothesis expressed by many researchers that FAN is the 
major toxic form of ammonia (Massé et al., 2014). Second, it has been reported that trace elements were crucial to the growth of microbes and also required for efficient anaerobic digestion at high ammonia levels; especially for the interspecies electron transfer (Banks et al., 2012). The cultivation medium of $C$. vulgaris, contains sufficient amounts of trace elements, such as Co and Mo (Mendez et al., 2013), which could have promoted the growth of bacteria and archaea under the extreme ammonia levels. Overall, the current study, using protein-rich microalgae as primary substrate, has shown for the first time that a successful continuous AD acclimation process to extremely high ammonia levels is possible.

\subsection{Microbial community dynamics}

Alpha diversity (Fig. 2a) based on Chao 1 bias-corrected index, decreased alongside with the increase of ammonia levels in both reactors. This indicates that only some of the initial microbiome members survived at higher ammonia toxicity levels and thus a more narrowed and specialized AD community was formed. Beta diversity (Fig. 2b and Fig. 2c) demonstrated a clear microbial dynamic change throughout the ammonia acclimation process. Additionally, the longest and shortest matrix distances were found between $\mathrm{P} 4$ and $\mathrm{P} 1$, and $\mathrm{P} 2$ and $\mathrm{P} 1$, respectively, for both reactors. This indicates that higher ammonia levels had bigger community differences compared to the baseline ammonia level (P1). The result was in agreement with a previous study, which declared that ammonia levels significantly affected the microbiome clustering of different biogas plants (De Vrieze et al., 2015).

\subsection{Microbiome composition}


The vast majority of AD microbial community throughout the whole experiment was composed by bacteria ( $98 \%$ of relative abundance on average). Proteobacteria (30\%-40\%), Firmicutes (20\%-30\%), followed by Bacteroidetes and WWE1 (both 3\%$10 \%$ ), were the most dominant phyla, as can be seen from the E-supplement file, in agreement with previous study (De Vrieze et al., 2015). Alphaproteobacteria and Clostridia were the most abundant classes, while Rhizobiales, Clostridiales and the uncultured MBA08 were predominant at order level.

The first and second most abundant bacterial OTUs (an average abundance of $22.09 \%$ and $6.50 \%$, respectively) belonged to Rhizobiaceae family. However, both OTUs showed no significant change of relative abundance during this acclimation process (Fig. 3). By performing a BLASTN search, the best matches for the two OTUs were identified with $100 \%$ identity to Shinella spp. and Rhizobium kunmingense, respectively. Shinella spp. was previously identified in a biogas reactor treating grass silage and lignocellulose substrate (Wang et al., 2010), and also found, with high relative abundance, in reactors with pure microalgae as substrate (Sanz et al., 2017). Thus, it was proposed by Sanz et al. (2017) that Shinella spp., may play a pivotal role in microalgae degradation, especially for some recalcitrant polysaccharides and glycoprotein matrix. The exact function of Shinella spp. during AD process is still unclear; however, the results of the current study indicate that its high abundance was not affected by the ammonia levels. Regarding the second abundant OTU, it seems that $R$. kunmingense was delivered into the reactors together with the microalgae feedstock (C. vulgaris). This is supported firstly by Wirth et al. (2015) who reported the presence of $R$. kunmingense in a two-stage biohydrogen and biogas reactor fed only with Chlamydomonas spp. and Scenedesmus spp. algae; and secondly by Kim et al. (2014) 
who found relative abundance of Rhizobium spp. was as high as $30.23 \%$ during $C$. vulgaris cultivation.

Among the highly abundant bacteria, 27 and 25 OTUs for R1 and R2, respectively, changed significantly from P1 to P4 (Fig. 4), indicating a sensibility of these microbes in respect to ammonia. Regarding microbes that seem favoured, 4 Clostridia, Wohlfahrtiimonas sp. 11 and Cloacamonae sp. 26 were the OTUs that significantly increased in relative abundance. Specifically, Clostridium sp. 13 was the most interesting bacterium, increasing by 37 and 60 folds $(0.1 \%$ in $\mathrm{P} 1$ to $3.7 \%-6.0 \%$ in $\mathrm{P} 4$, Fig. 3) for R1 and R2, respectively, and was found to be $95 \%$ similar to an isolated SAOB Clostridium ultunense (Schnürer, 1996). This result was in accordance with previous studies (Westerholm et al., 2011), which found C. ultunense increased significantly under elevated ammonia levels. It is known that SAOB are always coupled with hydrogen utilization methanogens (Hattori, 2008), thus the increased abundance of C. ultunense indicated a significant hydrogenotrophic methanogenic activity. Another noteworthy result was that order MBA08 (consisted of Clostridia sp. 5, Clostridia sp. 7, Clostridia sp. 10 and Clostridia sp. 16), increased from 9.3\% to 12.5\%. MBA08 was found in mesophilic AD processes with increased ammonia levels (Müller et al., 2016), and also in biogas upgrading reactors operating under a dominant hydrogenotrophic pathway (Kougias et al., 2017). Based on BLASTN search result, these OTUs showed 88-91\% identity to Hydrogenispora ethanolica, a carbohydrate-fermenting bacterium with the ability to produce hydrogen (Peng et al., 2014). Even though taxonomical and functional classification of this microbe needs further investigation, it still can be concluded that $H$. ethanolica can tolerate high ammonia levels. Regarding the OTU negatively influenced by ammonia, the most inhibited Cloacamonae sp. 2 was affiliated 
to WWE1 group, which was found in manure-based biogas reactors, and was assumed to participate in the cellulose catabolic processes (Limam et al., 2014). Thus, high abundance of Cloacamonae sp. 2 at P1 could be explained by the manure-based inoculum and the cattle manure used to start-up the reactors. The significant decrease in abundance was most probably caused by low ammonia tolerance.

Considering the archaeal community, Methanosarcina sp. 1 and Methanobrevibacter sp. 2 were the predominant methanogens at P1, with more than $30 \%$ and $60 \%$ of the archaea relative abundance, respectively $(0.45 \%$ and $0.8 \%$ of the total microbial community). However, at the highest ammonia level (P4), the two OTUs showed opposite behaviours: the relative abundance of Methanobrevibacter sp. 2 collapsed to less than $1 \%$, while Methanosarcina sp. 1 became the most abundant methanogen (almost 90\%). Moreover, Methanoculleus palmolei 3 emerged in $\mathrm{P} 4$ and became the second most abundant archaea (5-8\%). This impressive positive change of Methanosarcina spp. abundance contrasted with previous studies, which reported that hydrogenotrophic methanogens (i.e. Methanomicrobiales spp. and Methanobacteriales spp.) were predominant at high ammonia levels (Angenent et al., 2002; Fotidis et al., 2014a). However, it has been reported by Jarrell et al. (1987) that Methanosarcina barkeri can tolerate extremely high ammonia levels $\left(10 \mathrm{NH}_{4}{ }^{+}-\mathrm{N} \mathrm{L}^{-1}\right)$. In this study, based on BLASTN analysis, Methanosarcina sp. 1 was found to be equally similar to different Methanosarcina species (M. soligelidi/ acetivorans/ barkeri/ mazei) with $98 \%$ identity, thus is not possible to identify it at species level. Anyway, Methanosarcina sp. 1 ammonia tolerance could be explained by the known specific morphology of Methanosarcina genus; In detail, its large cell size and spherical shape was reported to form large multicellular structure (clusters) with higher volume/ surface ratio at high 
ammonia levels (Calli et al., 2005; Goberna et al., 2010). More over organisation in clusters could create a niche environment with lower ammonia concentrations due to ammonia concentration gradient from the surface of the cluster to the inner core. Another explanation could be the reported ability of some Methanosarcina species to shift their metabolic pathway into hydrogenotrophic methanogenesis under extreme conditions (e.g. high ammonia levels) (Demirel \& Scherer, 2008; Thauer et al., 2008). Since SAOB abundance increased significantly alongside with Methanosarcina spp. during this acclimation process (Fig. 3), there is the possibility that some of the Methanosarcina species were mediating the hydrogenotrophic pathway. However, assessing the methanogenic pathway of Methanosarcina spp. was out of the scope of the current study. Finally, Methanoculleus palmolei 3 increased in abundance, which was in agreement with a previous study where Methanoculleus spp. increased proportionally with the ammonia levels (Westerholm et al., 2012). However, not all hydrogenotrophic methanogens were able to cope with ammonia toxicity. In fact, the abundance of Methanobrevibacter sp. 2 decreased significantly during the acclimation process, indicating its limitation to thrive at extremely high ammonia levels.

\section{Conclusions}

The stepwise acclimation strategy used in the present study showcases the potential of utilizing protein-rich microalgae ( $3^{\text {rd }}$ generation biomass) as $\mathrm{AD}$ substrates and paves the way forward to use other protein-rich substrates (e.g. food waste, slaughterhouse waste etc.). Moreover, 16s rRNA sequencing showed a clear shift in the microbial dynamics throughout the acclimation process, which led to a narrower and specialized (ammonia tolerant) AD community. Surprisingly, facultative aceticlastic Methanosarcina spp. was the most dominant methanogen at extreme ammonia levels. 
This indicates that there are aceticlastic methanogens capable to thrive even under very hostile conditions (i.e. washout effect, extreme ammonia levels).

\section{Appendix A. Supplementary material}

E-supplementary data for this work can be found in e-version of this paper online.

Supplementary data 1: Fig S1. The estimated and measured TAN levels and calculated FAN concentration throughout the experimental period; Fig S2. Rarefaction curve of all microbial samples; Table S1. Sample name and the corresponding accession number in SRA database; Table S2. Statistics of the sequencing process and data analysis of the $16 \mathrm{~S}$ rRNA samples.

Supplementary data 2: Table S3. Taxonomic assignment of $16 \mathrm{~S}$ rRNA gene of interesting OTUs at different phases in R1 and R2.

\section{Acknowledgements}

The authors thank Hector Garcia for his technical support during the experiments. This work was supported by Energinet.dk under the project framework ForskEL "MicrobStopNH ${ }_{3}$-Innovative bioaugmentation strategies to tackle ammonia inhibition in anaerobic digestion process" (program no. 2015-12327) and projects (WW-ALGAS, ENE2013-45416-R and RYC-2014-16823) from Spanish Ministry of Economy and Competitiveness. Hailin Tian would like to thank for the financial support from China Scholarship Council.

\section{References}


[1] Ahring, B.K., Sandberg, M., Angelidaki, I. 1995. Volatile fatty acids as indicators of process imbalance in anaerobic digestors. Applied Microbiology and Biotechnology, 43, 559-565.

[2] Angelidaki, I., Ahring, B.K. 1994. Anaerobic thermophilic digestion of manure at different ammonia loads: Effect of temperature. Water Research, 28, 727-731.

[3] Angenent, L.T., Sung, S., Raskin, L. 2002. Methanogenic population dynamics during startup of a full-scale anaerobic sequencing batch reactor treating swine waste. Water Research, 36, 4648-4654.

[4] APHA. 2005. Standard Methods for the Examination of Water and Wastewater. American Public Health Association, Washington, DC.

[5] Banks, C.J., Zhang, Y., Jiang, Y., Heaven, S. 2012. Trace element requirements for stable food waste digestion at elevated ammonia concentrations. Bioresource Technology, 104, 127-35.

[6] Calli, B., Mertoglu, B., Inanc, B., Yenigun, O. 2005. Methanogenic diversity in anaerobic bioreactors under extremely high ammonia levels. Enzyme and Microbial Technology, 37, 448-455.

[7] De Vrieze, J., Saunders, A.M., He, Y., Fang, J., Nielsen, P.H., Verstraete, W., Boon, N. 2015. Ammonia and temperature determine potential clustering in the anaerobic digestion microbiome. Water Research, 75, 312-323.

[8] Demirel, B., Scherer, P. 2008. The roles of acetotrophic and hydrogenotrophic methanogens during anaerobic conversion of biomass to methane: a review. Reviews in Environmental Science and Bio/Technology, 7, 173-190.

[9] Edgar, R.C. 2004. MUSCLE: multiple sequence alignment with high accuracy and high throughput. Nucleic Acids Research, 32, 1792-1797. 
[10] Fotidis, I.A., Karakashev, D., Angelidaki, I. 2014a. The dominant acetate degradation pathway/methanogenic composition in full-scale anaerobic digesters operating under different ammonia levels. International Journal of Environmental Science and Technology, 11, 2087-2094.

[11] Fotidis, I.A., Wang, H., Fiedel, N.R., Luo, G., Karakashev, D.B., Angelidaki, I. 2014b. Bioaugmentation as a solution to increase methane production from an ammonia-rich substrate. Environmental Science \& Technology, 48, 7669-76.

[12] Goberna, M., Gadermaier, M., García, C., Wett, B., Insam, H. 2010. Adaptation of methanogenic communities to the cofermentation of cattle excreta and olive mill wastes at $37{ }^{\circ} \mathrm{C}$ and $55^{\circ} \mathrm{C}$. Applied and Environmental Microbiology, 76, 65646571.

[13] Hansen, K.H., Angelidaki, I., Ahring, B.K. 1999. Improving thermophilic anaerobic digestion of swine manure. Water Research, 33, 1805-1810.

[14] Hattori, S. 2008. Syntrophic Acetate-Oxidizing Microbes in Methanogenic Environments. Microbes and Environments, 23, 118-127.

[15] Jarrell, K.F., Saulnier, M., Ley, A. 1987. Inhibition of methanogenesis in pure cultures by ammonia, fatty acids, and heavy metals, and protection against heavy metal toxicity by sewage sludge. Canadian Journal of Microbiology, 33, $551-554$.

[16] Karakashev, D., Batstone, D.J., Angelidaki, I. 2005. Influence of environmental conditions on methanogenic compositions in anaerobic biogas reactors. Applied and Environmental Microbiology, 71, 331-8. 
[17] Karim, K., Hoffmann, R., Thomas Klasson, K., Al Dahhan, M.H. 2005. Anaerobic digestion of animal waste: Effect of mode of mixing. Water Research, 39, 35973606.

[18] Kim, B.H., Ramanan, R., Cho, D.H., Oh, H.M., Kim, H.S. 2014. Role of Rhizobium, a plant growth promoting bacterium, in enhancing algal biomass through mutualistic interaction. Biomass and Bioenergy, 69, 95-105.

[19] Koster, I.W., Lettinga, G. 1988. Anaerobic digestion at extreme ammonia concentrations. Biological Wastes, 25, 51-59.

[20] Kougias, P.G., Treu, L., Benavente, D.P., Boe, K., Campanaro, S., Angelidaki, I. 2017. Ex-situ biogas upgrading and enhancement in different reactor systems. Bioresource Technology, 225, 429-437.

[21] Limam, R.D., Chouari, R., Mazéas, L., Wu, T., Li, T., Grossin Debattista, J., Guerquin Kern, J.L., Saidi, M., Landoulsi, A., Sghir, A., Bouchez, T. 2014. Members of the uncultured bacterial candidate division WWE1 are implicated in anaerobic digestion of cellulose. MicrobiologyOpen, 3, 157-167.

[22] Liu, T., Sung, S. 2002. Ammonia inhibition on thermophilic aceticlastic methanogens. Water Science and Technology, 45, 113-120.

[23] Liu, Y., Whitman, W.B. 2008. Metabolic, phylogenetic, and ecological diversity of the methanogenic archaea. Annals of the New York Academy of Sciences, 1125, 171-89.

[24] Lyu, Z., Lu, Y. 2015. Comparative genomics of three Methanocellales strains reveal novel taxonomic and metabolic features. Environmental Microbiology Reports, 7, 526-537. 
[25] Mahdy, A., Fotidis, I.A., Mancini, E., Ballesteros, M., Gonzalez-Fernandez, C., Angelidaki, I. 2017. Ammonia tolerant inocula provide a good base for anaerobic digestion of microalgae in third generation biogas process. Bioresource Technology, 225, 272-278.

[26] Mahdy, A., Mendez, L., Ballesteros, M., González-Fernández, C. 2015. Protease pretreated Chlorella vulgaris biomass bioconversion to methane via semicontinuous anaerobic digestion. Fuel, 158, 35-41.

[27] Maity, J.P., Bundschuh, J., Chen, C.-Y., Bhattacharya, P. 2014. Microalgae for third generation biofuel production, mitigation of greenhouse gas emissions and wastewater treatment: Present and future perspectives - A mini review. Energy, $78,104-113$.

[28] Massé, D.I., Rajagopal, R., Singh, G. 2014. Technical and operational feasibility of psychrophilic anaerobic digestion biotechnology for processing ammonia-rich waste. Applied Energy, 120, 49-55.

[29] Mendez, L., Mahdy, A., Timmers, R.A., Ballesteros, M., González-Fernández, C. 2013. Enhancing methane production of Chlorella vulgaris via thermochemical pretreatments. Bioresource Technology, 149, 136-141.

[30] Müller, B., Sun, L., Westerholm, M., Schnürer, A. 2016. Bacterial community composition and fhs profiles of low- and high-ammonia biogas digesters reveal novel syntrophic acetate-oxidising bacteria. Biotechnology for Biofuels, 9, 48.

[31] Nielsen, H.B., Angelidaki, I. 2008. Strategies for optimizing recovery of the biogas process following ammonia inhibition. Bioresource Technology, 99, 7995-8001. 
[32] Parkin, G.F., Speece, R.E., Yang, C.H.J., Kocher, W.M. 1983. Response of methane fermentation systems to industrial toxicants. Journal of the Water Pollution Control Federation, 55, 44-53.

[33] Parks, D.H., Beiko, R.G. 2010. Identifying biologically relevant differences between metagenomic communities. Bioinformatics, 26, 715-721.

[34] Peng, X., Borner, R.A., Nges, I.A., Liu, J. 2014. Impact of bioaugmentation on biochemical methane potential for wheat straw with addition of Clostridium cellulolyticum. Bioresour Technol, 152, 567-71.

[35] Saeed, A.I., Bhagabati, N.K., Braisted, J.C., Liang, W., Sharov, V., Howe, E.A., Li, J., Thiagarajan, M., White, J.A., Quackenbush, J. 2006. [9] TM4 Microarray Software Suite. in: Methods in Enzymology, Vol. Volume 411, Academic Press, pp. 134-193.

[36] Sanz, J.L., Rojas, P., Morato, A., Mendez, L., Ballesteros, M., González-Fernández, C. 2017. Microbial communities of biomethanization digesters fed with raw and heat pre-treated microalgae biomasses. Chemosphere, 168, 1013-1021.

[37] Schnürer, A., Bernhard Schink, and Bo H. Svensson. 1996. Clostridium ultunense sp. nov., a mesophilic bacterium oxidizing acetate in syntrophic association with a hydrogenotrophic methanogenic bacterium. International Journal of Systematic and Evolutionary Microbiology, 46, 1145-1152.

[38] Schnürer, A., Nordberg, Å. 2008. Ammonia, a selective agent for methane production by syntrophic acetate oxidation at mesophilic temperature. Water Science and Technology, 57, 735-740. 
[39] Siegert, I., Banks, C. 2005. The effect of volatile fatty acid additions on the anaerobic digestion of cellulose and glucose in batch reactors. Process Biochemistry, 40, 3412-3418.

[40] Thauer, R.K., Kaster, A.K., Seedorf, H., Buckel, W., Hedderich, R. 2008. Methanogenic archaea: ecologically relevant differences in energy conservation. Nature Reviews Microbiology, 6, 579-91.

[41] Tian, H., Fotidis, I.A., Mancini, E., Angelidaki, I. 2017. Different cultivation methods to acclimatise ammonia-tolerant methanogenic consortia. Bioresource Technology, 232, 1-9.

[42] Tsapekos, P., Kougias, P.G., Treu, L., Campanaro, S., Angelidaki, I. 2017. Process performance and comparative metagenomic analysis during co-digestion of manure and lignocellulosic biomass for biogas production. Applied Energy, 185, Part 1, 126-135.

[43] Wang, H., Vuorela, M., Keränen, A.-L., Lehtinen, T.M., Lensu, A., Lehtomäki, A., Rintala, J. 2010. Development of microbial populations in the anaerobic hydrolysis of grass silage for methane production. FEMS Microbiology Ecology, 72, 496-506.

[44] Werner, J.J., Garcia, M.L., Perkins, S.D., Yarasheski, K.E., Smith, S.R., Muegge, B.D., Stadermann, F.J., DeRito, C.M., Floss, C., Madsen, E.L., Gordon, J.I., Angenent, L.T. 2014. Microbial Community Dynamics and Stability during an Ammonia-Induced Shift to Syntrophic Acetate Oxidation. Applied and Environmental Microbiology, 80, 3375-3383. 
[45] Westerholm, M., Leven, L., Schnurer, A. 2012. Bioaugmentation of syntrophic acetate-oxidizing culture in biogas reactors exposed to increasing levels of ammonia. Applied and Environmental Microbiology, 78, 7619-25.

[46] Westerholm, M., uuml, ller, B., Arthurson, V., Schn, uuml, rer, A. 2011. Changes in the Acetogenic Population in a Mesophilic Anaerobic Digester in Response to Increasing Ammonia Concentration. Microbes and Environments, 26, 347-353.

[47] Wirth, R., Lakatos, G., Maróti, G., Bagi, Z., Minárovics, J., Nagy, K., Kondorosi, É., Rákhely, G., Kovács, K.L. 2015. Exploitation of algal-bacterial associations in a two-stage biohydrogen and biogas generation process. Biotechnology for Biofuels, 8, 59.

[48] Yenigün, O., Demirel, B. 2013. Ammonia inhibition in anaerobic digestion: A review. Process Biochemistry, 48, 901-911.

[49] Zhang, L., Lee, Y.W., Jahng, D. 2012. Ammonia stripping for enhanced biomethanization of piggery wastewater. Journal of Hazardous Materials, 199$200,36-42$.

[50] Zhang, Y., Angelidaki, I. 2015. Submersible microbial desalination cell for simultaneous ammonia recovery and electricity production from anaerobic reactors containing high levels of ammonia. Bioresource Technology, 177, 2339. 


\section{Highlights}

- Successful acclimation of methanogenic culture to extreme ammonia levels in CSTR

- Efficient utilization of a $3^{\text {rd }}$ generation biomass as biomethanation substrate

- The most abundant bacterium (Shinella spp.) was not affected by the ammonia levels

- C. ultunense increased significantly its abundance during the acclimation process

- Methanosarcina spp. was the most abundant methanogen at the highest ammonia levels 
Table 1. Characteristics of the inoculum and substrates.

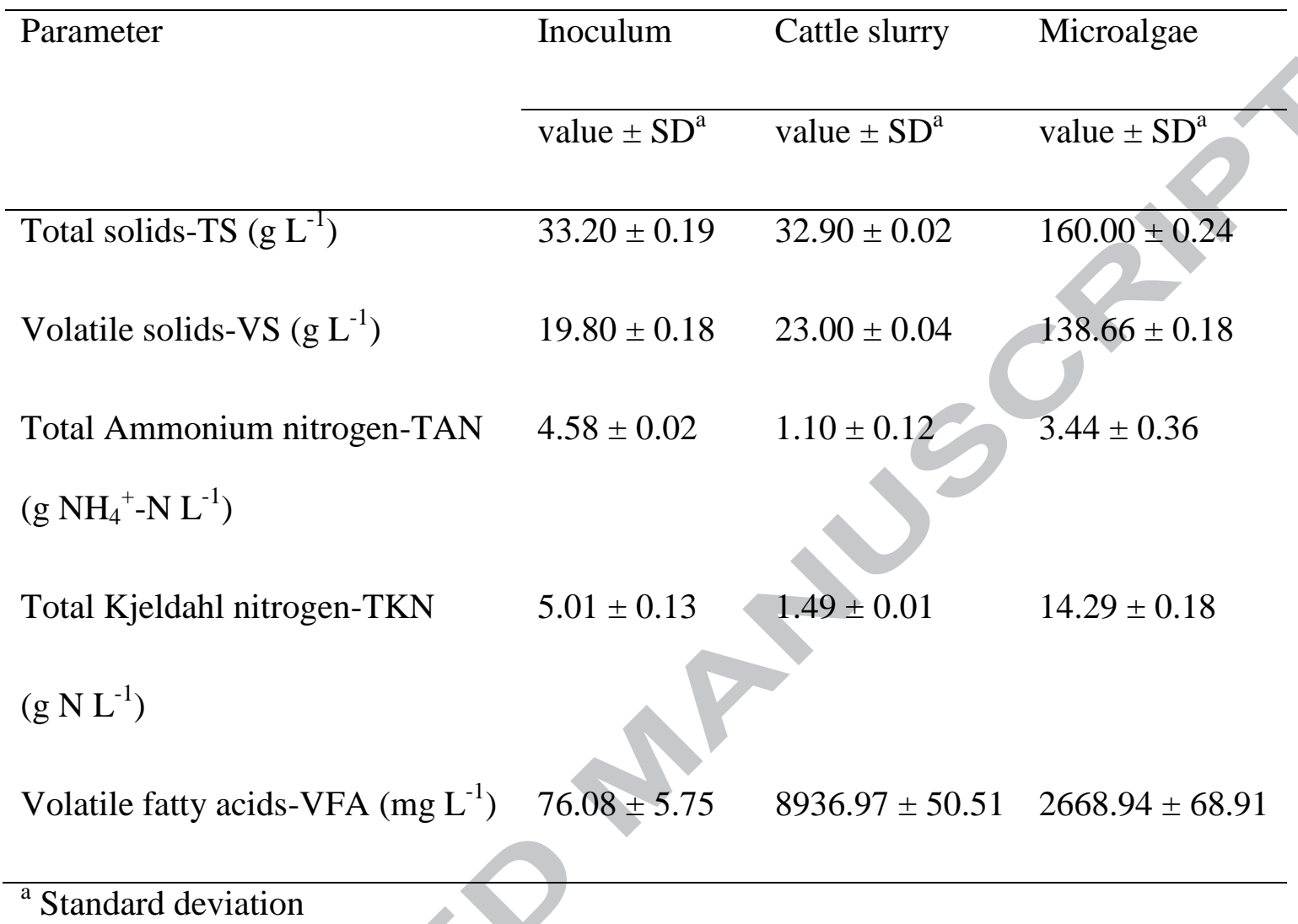

Table 2. Operational parameters in different experimental phases.

\begin{tabular}{|c|c|c|c|c|}
\hline & Phase 1 & Phase 2 & Phase 3 & Phase 4 \\
\hline & $(\mathrm{P} 1)^{*}$ & $(\mathrm{P} 2)$ & (P3) & $(\mathrm{P} 4)$ \\
\hline Days & $0-28$ & $29-51$ & $52-98$ & $99-133$ \\
\hline Substrate & \multicolumn{4}{|c|}{$20 \%$ cattle slurry $+80 \%$ microalgae (based on VS) } \\
\hline Organic loading rate-OLR & \multicolumn{4}{|c|}{$1.95 \pm 0.1$} \\
\hline$\left(g_{V S ~ L}^{-1} d^{-1}\right)$ & & & & \\
\hline Total ammonium nitrogen-TAN ( $\mathrm{g}$ & $3.3-3.8$ & $4.3-6.0$ & $6.5-8.0$ & $8.5-10$ \\
\hline
\end{tabular}


$\left.\mathrm{NH}_{4}{ }^{+}-\mathrm{N} \mathrm{L}^{-1}\right)$

*P1 was used as the baseline before acclimation strategy with addition of $\mathrm{NH}_{4} \mathrm{Cl}$. 


\section{Figure Captions}

Fig. 1. The performance parameters of the reactors a) methane yield, b) VFA and c) pH at different experimental phases. Arrows indicate the sampling time for microbial analysis.

Fig. 2. Alpha Diversity (a) based on Chao 1 bias-corrected index; Beta diversity of the triplicate samples in R1 (b) and R2 (c). Principal components (PC) 1 and 2 explained $62.3 \%$ and $21.6 \%$ of community variation for $\mathrm{R} 1$, and $65.5 \%$ and $19.5 \%$ for R2, respectively.

Fig. 3. Relative abundance (\%) (left part) and the corresponding folds change (right part) for the interesting archaea in reactor R1 (a) and R2 (b), and bacteria in reactor R1 (c) and R2 (d).

Fig. 4. OTUs that changed significantly $(\mathrm{p}<0.05)$ in $\mathrm{R} 1$ (a) and $\mathrm{R} 2$ (b) in the comparison between P4 and P1. 


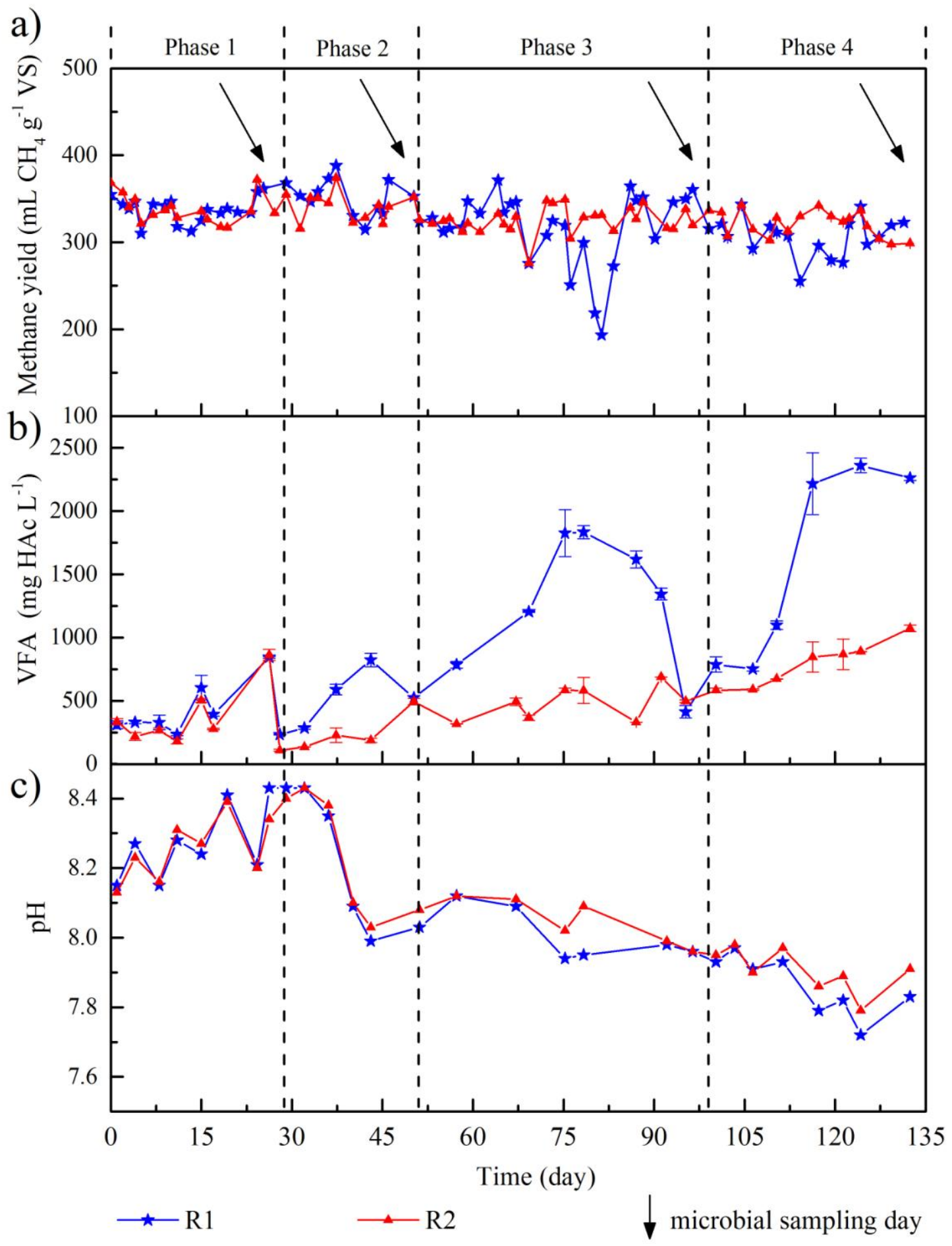



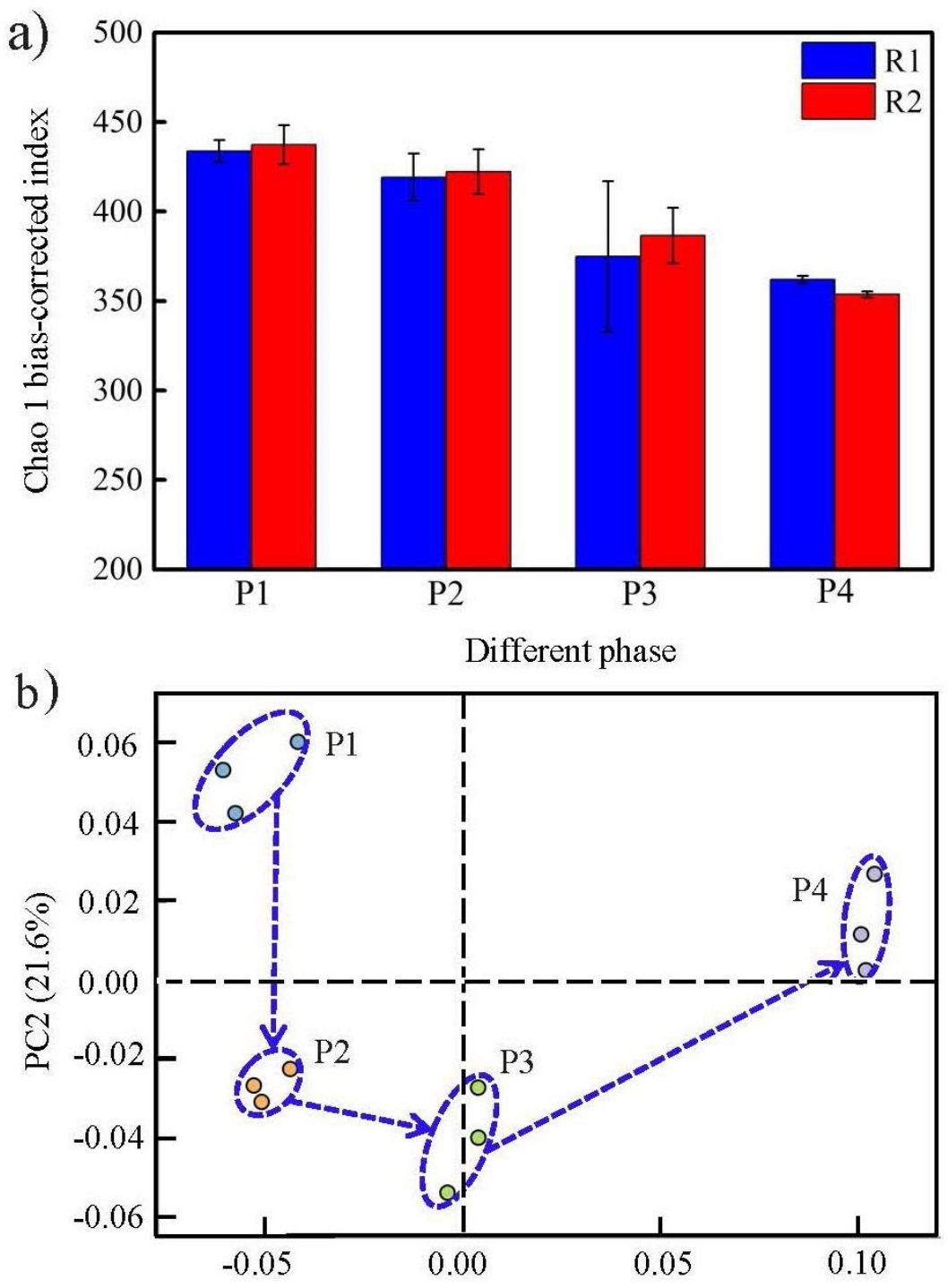

PC1 (62.3\%)

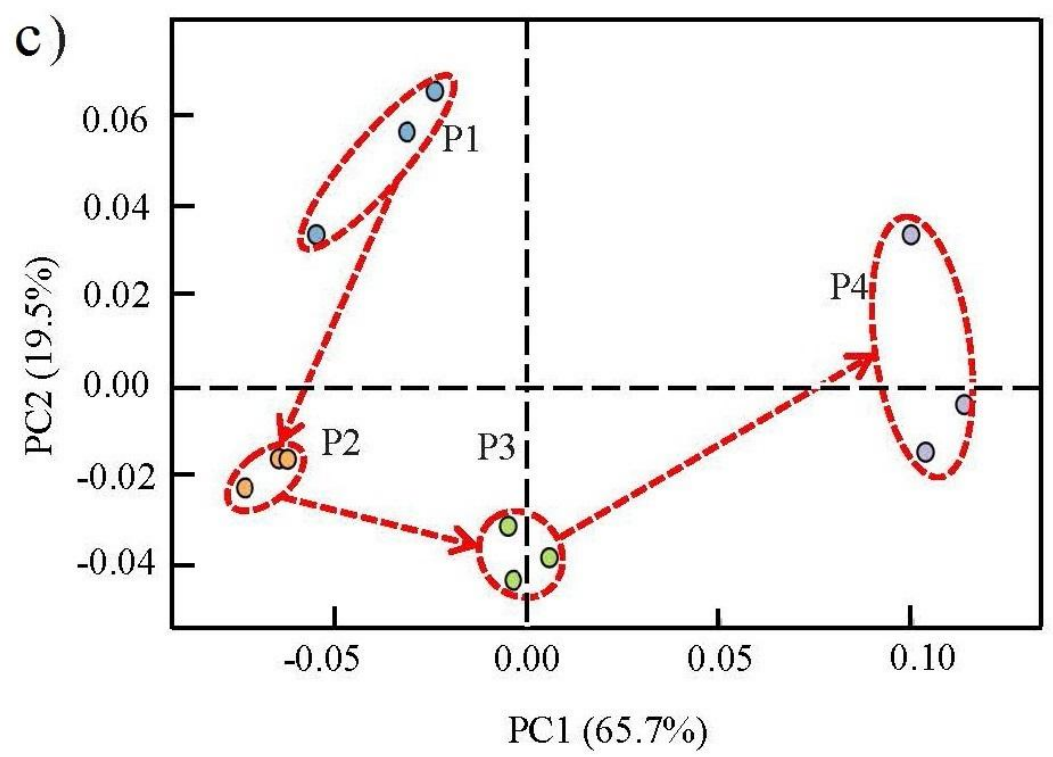


a)

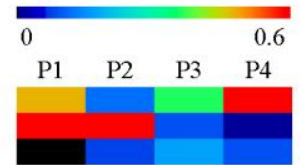

c)
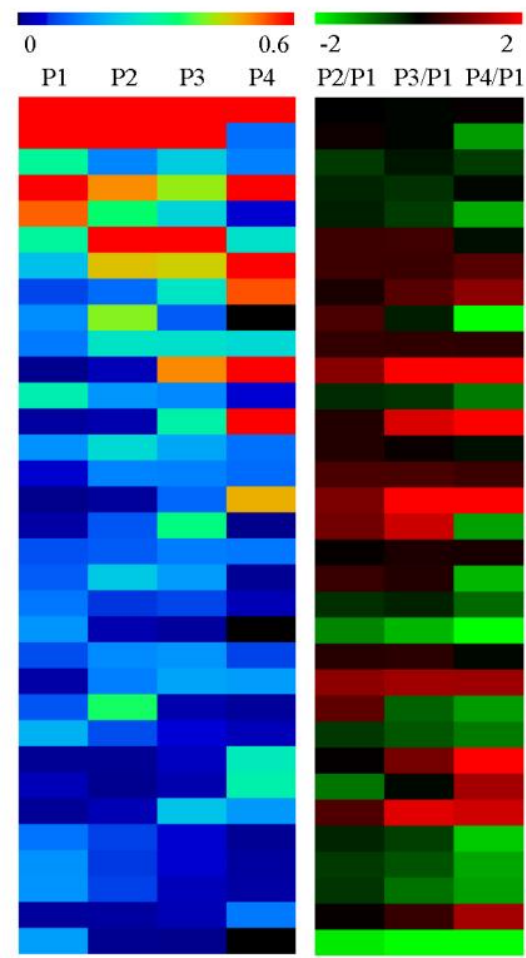

$\begin{array}{llll}\mathrm{P} 3 / \mathrm{P} 1 & \mathrm{P} 4 / \mathrm{P} 1\end{array}$

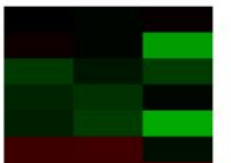

$\begin{array}{lll}2 & 2 \\ \mathrm{P} 2 / \mathrm{P} 1 & \mathrm{P} 3 / \mathrm{P} 1 & \mathrm{P} 4 / \mathrm{P} 1\end{array}$

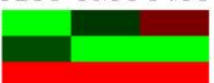

b)

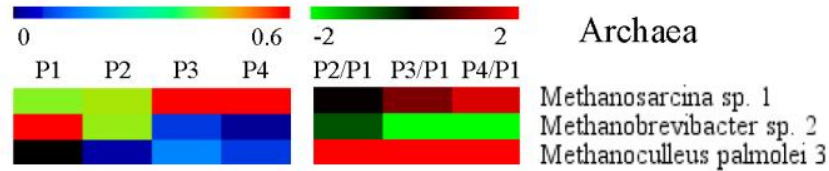

d)
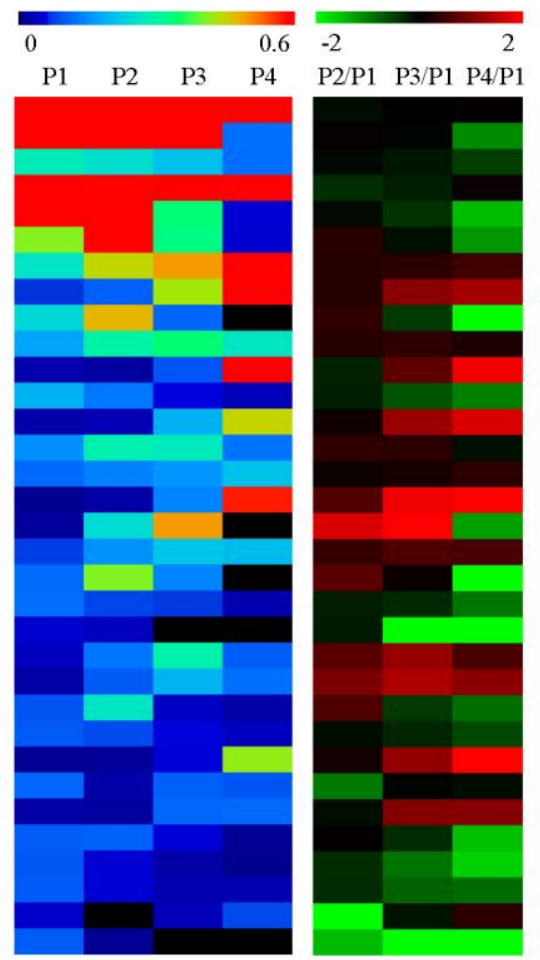

\section{Bacteria}

Shinella sp. 1

Cloacamonae sp. 2

Clostridia sp. 3

Rhizobium kunmingense 4

Clostridia sp. 5

Bacteroidales sp. 6

Clostridia sp. 7

Clostridia sp. 8

Serpens sp. 9

Clostridia sp. 10

Wohlfahrtimonas $\mathrm{sp} .11$

Alkaliphilus sp. 12

Clostridium sp. 13

Clostridia sp. 14

Bacteroidales sp. 15

Clostridia sp. 16

Pseudomonas caeni 17

Syntrophomonas sapovorans 18

Erysipelotrichales sp. 19

Clostridia sp. 20

Clostridia sp. 21

Bacteroides coprosuis 22

Rhodopseudomonas sp. 23

Clostridia sp. 24

Syntrophomonas sp. 25

Cloacamonae sp. 26

Xenorhabdus sp. 27

Xenorhablus sp. 27

Bacteroidales sp.

Clostridia sp. 29

Aminobacterium colombiense 30

Syntrophomonas bryantii 31

Pseudomonas sp. 32

Cloacamonae sp. 33 
a)

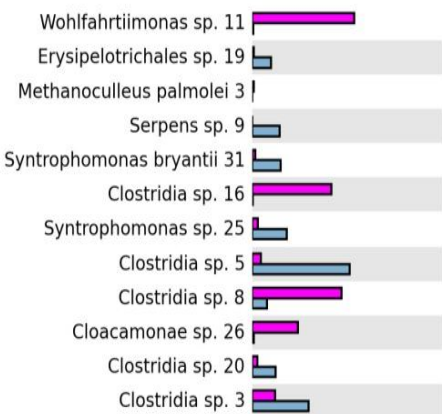
Clostridia sp. 29

Cloacamonae sp. 2 2 Xenorhabdus sp. 27

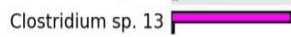
Alkaliphilus sp. 12 Bacteroidales sp. 28 Pseudomonas caeni 17 | Cloacamonae sp. 33 ๒ Rhodopseudomonas sp. 23 Pseudomonas sp. $32 \rightleftharpoons$ Bacteroidales sp. 15 品 Clostridia sp. $21 \boxminus$ Methanosarcina sp. 1 品 Methanobrevibacter sp. 2 ط Clostridia sp. $10 \square$ Clostridia sp. 24 ط Clostridia sp. 7 0.0 $\square$ R1-P4 $\square$ R1-P1 Mean proportion (\%) b)

Rhodopseudomonas sp. 23 Aminobacterium colombiense 30 与 Alkaliphilus sp. 12 Cloacamonae sp. 2 Bacteroidales sp. 6 Cloacamonae sp, 26 Clostridia sp. 8

Methanobrevibacter sp. 2 • Clostridia sp. 5

Cloacamonae sp. 33 曰 Clostridia sp. 24 与 Clostridia sp. 16 Wohlfahrtiimonas sp. 11 Methanoculleus palmolei 3 । Clostridia sp. 29 与 Syntrophomonas bryantii 31 ط Clostridium sp. $1 3 \longdiv { \square }$ Clostridia sp. 3 ב Syntrophomonas sp. 25 ש Erysipelotrichales sp. 19 Clostridia sp. 20 Syntrophomonas sapovorans 18 Clostridia sp. 21 ב Bacteroidales sp. 28 ק Serpens sp. 9 Pseudomonas caeni 17 , Clostridia sp. 7 Methanosarcina sp. 1

$\square$ R2-P4 $\square$ R2-P1 Mean proportion (\%)
$95 \%$ confidence intervals

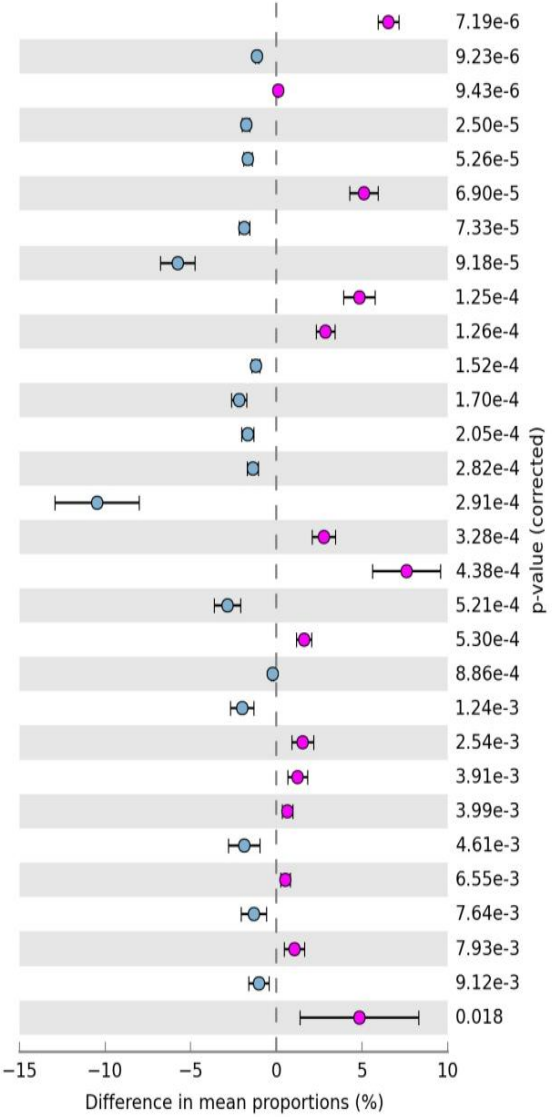

$95 \%$ confidence intervals

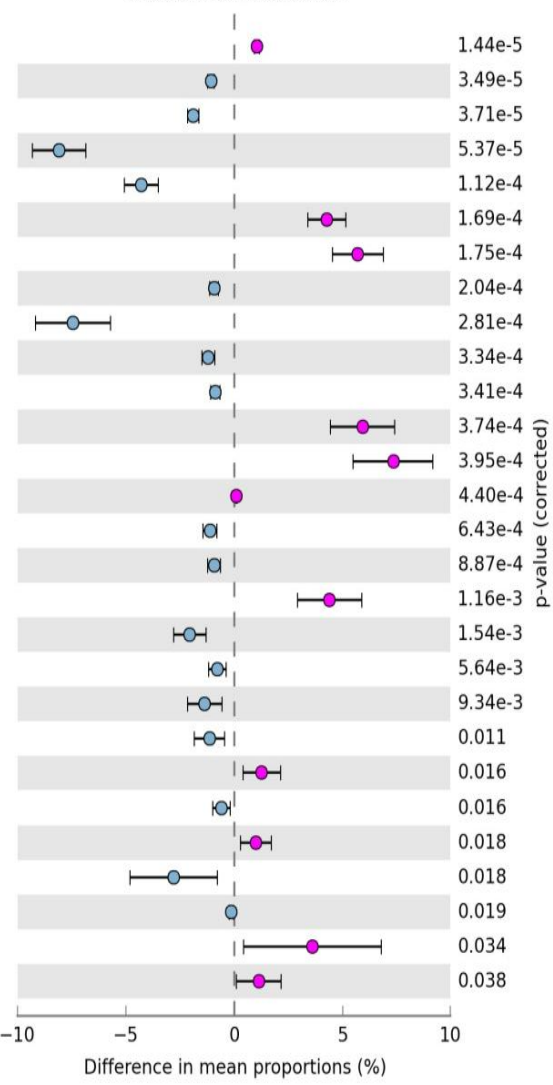

